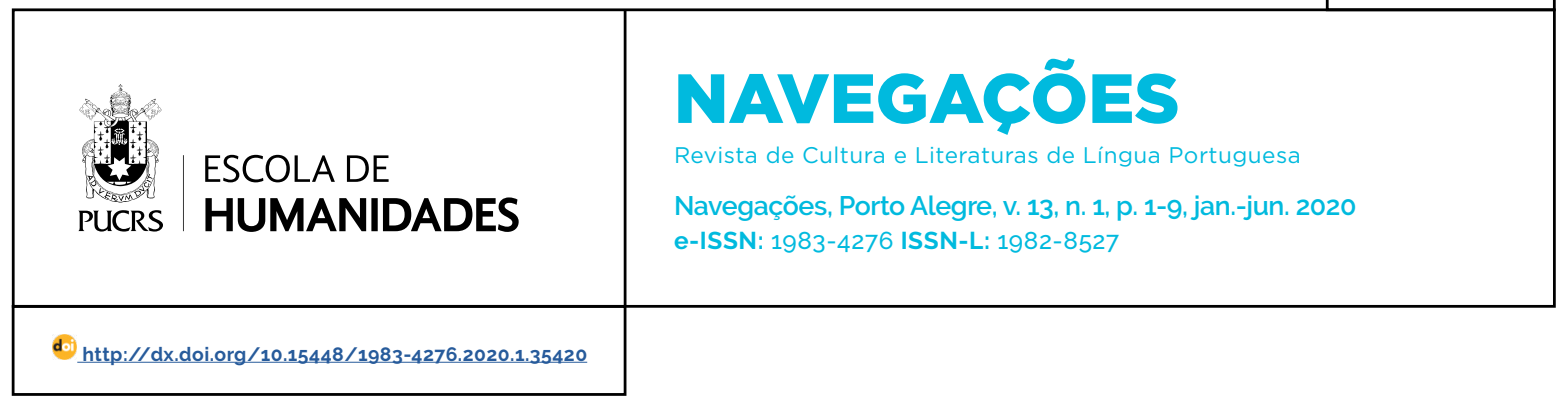

SEÇÃO: ENSAIOS

\title{
O lugar do sujeito contemporâneo no sertão: o tradicional e o moderno em Galileia, de Ronaldo Correia de Brito ${ }^{1}$
}

\author{
The place of the contemporary individual in the Backlands: the traditional and the \\ modern in Galileia, by Ronaldo Correia de Brito
}

\author{
Hayonara Medeiros ${ }^{2}$ \\ orcid.org/0000-0001-7891-4820 \\ hayonara_medeiros@hotmail.com
}

\section{André Tessaro Pelinser ${ }^{2}$ orcid.org/0000-0001-9756-0116 andre.pelinser@gmail.com}

Recebido em: 28 ago. 2019. Aprovado em: 12 nov. 2019. Publicado em: 10 ago. 2020.
Resumo: O regionalismo costuma ser associado pela crítica literária a termos arcaicos e ultrapassados, o que tem influenciado a opinião dos próprios escritores brasileiros. Ao longo do tempo, a crítica tem alimentado visões negativas sobre o regionalismo, ligando-o frequentemente a literaturas de descrição ambiental, a movimentos restritos e ao gosto pelo pitoresco e exótico. Em razão dessa perspectiva que desassocia o regionalismo de uma ficção bem elaborada, os escritores contemporâneos, muitas vezes, negam qualquer relação entre sua obra e esse movimento literário. Por meio deste trabalho, discutimos as formulações do regionalismo contemporâneo presentes na obra de Ronaldo Correia de Brito, bem como as percepções acerca dessa corrente literária veiculadas publicamente pelo autor. Para tanto, são analisados o romance intitulado Galileia e entrevistas concedidas por Correia de Brito. A partir das análises, pode-se compreender que o autor apropria-se da matéria regional, como o espaço do sertão nordestino, e de muitos conhecimentos advindos da cultura popular e caracteristicos dessa região. A obra desenvolve-se a partir de três personagens principais - Adonias, Ismael e Davi -, por meio dos quais o autor põe em cena trânsitos entre espaços periféricos do interior do Brasil e espaços comumente associados a centralidade. fazendo com que emerjam questões relativas à identidade regional. Apesar disso. o autor nega qualquer relação da sua obra com a corrente literária regionalista. Palavras-chave: Regionalismo. Sertão. Identidade. Galileia. Ronaldo Correia de Brito.

Abstract: Regionalism is often associated by literary criticism with archaic and outdated terms, and this practice has influenced the opinion of Brazilian writers themselves. Over time, criticism has nurtured negative views on regionalism, frequently linking it to literatures of environmental description, restricted movements, and a taste for the picturesque and exotic. Because of this perspective that disassociates regionalism from well-crafted fiction, contemporary writers often deny any relationship between their work and this literary movement. In this paper, we discuss the formulations of contemporary regionalism present in the work of Ronaldo Correia de Brito, as well as the perceptions about this literary current publicly conveyed by the author. For that purpose, the novel entitled Galileia and interviews by Correia de Brito are analyzed. From the analysis, it is possible to understand that the author appropriates the regional matter, such as the space known as sertão, and of much knowledge coming from the popular culture and characteristics of this region. The work develops from three main characters - Adonias, Ismael and Davi -, through which the author sets in motion transits between peripheral spaces of the interior of Brazil and spaces commonly associated with centrality, causing questions regarding the regional identity to arise. Nevertheless, the author denies any relation of his work with the regionalist literary current.

Keywords: Regionalism. Sertão. Identity. Galileia. Ronaldo Correia de Brito. 


\section{O problema do regionalismo}

A questão do regionalismo na literatura brasileira remonta ao séc. XIX. De acordo com Juliana Santini (2014, p. 116), Franklin Távora deseja deslocar a base da representação da prosa de ficção brasileira para o Norte do País, por estar mais afastada do litoral e da influência colonizadora. Na intenção de postular uma visão de literatura propriamente brasileira, Távora publica O Cabeleira, em 1876, acrescido de um prefácio, que registra o interesse do autor em dividir a literatura em duas, uma do Norte e outra do Sul, sendo a do Norte mais brasileira e não importada como a outra.

Em razão da necessidade de criar uma identidade e independência literária para o País, autores adotam a exaltação da cor local, enaltecendo as características geralmente voltadas a uma dada região. Segundo Santini, nesse ponto se encontra a origem do romance regionalista no Brasil, a qual se liga à

tentativa de dar forma a esse desejo de construir uma imagem da nação a partir do trato com o dado local que, nesse momento, longe ainda da consciência da diversidade regional, aparece como epítome de uma nação nova, grandiosa, que quer firmar sua independência no campo da política e da literatura (SANTINI, 2014, p. 116).

Respondendo à necessidade de construção de uma identidade literária nacional, autores põem em foco a exaltação das caracteristicas das diversas regiões do País em suas obras. A partir disso, eles constroem narrativas baseadas em descrições às vezes pitorescas de um certo local, configurando assim obras que focalizam e enaltecem os traços distintivos de uma dada região. Ao abordar a literatura desse periodo, a crítica literária tem construído uma visão negativa sobre tais textos, atrelando-os sempre ao fracasso, ao invés de fazer uma distinção entre obras boas e ruins, mas sempre pertencentes à mesma corrente literária. Em oposição a esse pensamento, a crítica tem rotulado a maioria das obras que possuem esse caráter descritivo como de má qualidade, ao passo que expurga as que conseguem transpor essas descrições e atingem o sucesso. A rejeição dos autores ao estilo literário regionalista é algo que advém desse posicionamento crítico, pensamento esse que influenciou os escritores durante longo periodo, e que ainda afeta artistas contemporâneos. Mário de Andrade, um dos precursores dessa visão negativa, conceitua o regionalismo, em 1928, como algo restrito, caracterizando-o como:

Regionalismo é mate aqui, borracha ali [...] pobreza sem humildade [...] caipirismo e saudosismo, comadrismo que não sai do beco e, o que é pior, se contenta com o beco. [...] Regionalismo, esse não adianta nada nem para a consciência da nacionalidade. Antes a conspurca e depaupera- Lhe estreitando por demais o campo de manifestação e, por isso, a realidade. $\mathrm{O}$ regionalismo é uma praga antinacional. Tão praga como imitar a música italiana ou ser influenciado pelo estilo português (ANDRADE, 1928 apud LEITE, 1994, p. 669).

Em História da literatura brasileira: prosa de ficção, Lúcia Miguel Pereira dedica um capitulo da sua obra para falar sobre o regionalismo, fazendo algumas considerações que influenciaram direta e indiretamente autores e criticos. Para Miguel Pereira, regionalismo corresponde a

[...] fixação de tipos, costumes e linguagem locais, cujo conteúdo perderia a significação sem esses elementos exteriores, e que se passem em ambientes onde os hábitos e estilos de vida se diferenciem dos que imprimem a civilização niveladora (1988, p. 175).

Por consequência, criou-se uma distinção entre obras boas e ruins, partindo do pressuposto de que ruim seria a obra regionalista, ao passo que a obra de qualidade seria aquela que retratava o universal. É Marisa Lajolo quem fornece a descrição dessa problemática:

Mas a inclusão de um texto na categoria regionalismo não é neutra: no limite regionalismo e regionalista são designações que recobrem, desvalorizando, autores e textos que não fazem da cidade moderna matriz de sua inspiração, nem da sua narrativa urbana padrão de linguagem. Obras e autores regionalistas - salvo exceções como alguns romancistas de 30 e as veredas sertanejas de Guimarães 
Rosa - costumam ser vistos pela crítica (e consequentemente pelas histórias literárias) como esteticamente inferiores, sendo a superioridade da produção literária não regionalista vinculada à sua universalidade, categoria também responsável pela redenção de escritores como Graciliano Ramos e Guimarães Rosa que em nome da abrangência de sua obra alçam voo da vala comum do regionalismo (LAJOLO, 2003, p. 327)

Por isso, reiteramos que, conforme já afirmado por Pelinser (2010, p. 107), nesse processo, é possivel identificar na historiografia e na tradição crítica brasileira uma sutil, mas sempre presente, necessidade de expurgar a marca do regional de determinados textos, como se essa pecha configurasse, per se, um demérito qualitativo.

\section{A visão autoral}

Em decorrência da construção negativa em torno do regionalismo, autores contemporâneos procuram dissociar-se dessa corrente literária, propagando discursos que, na tentativa de evitar preconceitos, por vezes acabam contribuindo para consolidá-los. Ronaldo Correia de Brito, autor da obra Galileia, em entrevista concedida ao Jornal Tribuna Feirense, de Feira de SantanaBA, quando questionado sobre uma retomada da temática do sertão, tece a seguinte consideração:

Essa cartilha nos prestou um grande desserviço. Regionalismo virou palavrão. Chamar um autor de regionalista é uma maneira de diminuir o valor do seu trabalho, reduzi-lo a estereótipos, enquadrá-lo em chavões, tratá-lo com preconceito e deboche. Pior do que ser chamado de regionalista só mesmo ser chamado de folclórico. Ou de contador de causos. Escrevi um artigo para a revista Continente com o título Regionalista é a Mãe. O título foi censurado. É como se nada tivesse acontecido nas bandas de cá desde 1930, o mundo houvesse parado, e nós ainda escrevêssemos com bico de pena. Isto ocorre no mundo inteiro, e no Brasil não seria diferente. Quem detém o poder econômico, o poder da mídia, dita as normas de mercado, estabelece os critérios de qualificação e desqualificação. Estabelece até um modelo de crítica, eo ensina nas universidades. É exemplar um ensaio de Mário de Andrade sobre a poesia de Ascenso Ferreira, alertando para o risco de o poeta cair na tipicidade. ele mesmo um regionalista de carteira, porque não há romance mais cheio de tipicidades do que Macunaima, ou que mais mereça o adjetivo de regionalista (MELO, [2005], grifo nosso).

Na mesma medida em que o autor recusa sua vinculação ao título de regionalista, ele tece observações sobre como se constrói a crítica literária, argumentando que ela advém de um pensamento político e que quem detém esse poder dita as normas. A percepção sobre o regionalismo provém de uma dicotomia entre universal e regional, na qual a "civilização niveladora" (PEREIRA, 1988, p. 175) dita como acontece a recepção crítica dessas obras, interferindo diretamente na forma como são recebidas pelo público e na forma como os autores lidam com a questão.

A relação delicada, por vezes problemática, entre Ronaldo Correia de Brito e o regionalismo é descrita em uma reportagem publicada pela Folha de S. Paulo, na qual o escritor rejeita o rótulo de regionalista: "O que faço não tem nada a ver com o manifesto regionalista, com os planos e pressupostos da época" (VENCEDOR..., [2009]).

Mas a negação do autor ao regionalismo não está apenas nas entrevistas, faz-se presente também na sua obra, em mais de um momento, a exemplo da seguinte passagem de Galileia: "Quer saber de uma coisa, Adonias? Regionalista é a mãe. E quer saber outra? Sinto-me acuado" (BRITO, 2009, p. 164). No decorrer do romance nos deparamos com negações, por vezes diretas e outras mais sutis, a essa corrente literária. Porém, em alguns momentos essa relação se torna contraditória, na qual o autor, por meio do narrador, expõe uma visão mais positiva:

- Ninguém precisa viver fora de seu pais para escrever um bom romance. [...]

- Nunca pensei em ir embora de minha terra. Leio o possivel, me informo sobre o que acontece no mundo, mas não fui muito longe, nas poucas viagens que fiz (BRITO, 2009, p. 165).

Essa visão conflitante sobre o regionalismo vai sendo construída a partir da associação a um personagem, Tio Salomão, descrito como 
arcaico e ultrapassado. Em diversos momentos, observa-se uma necessidade do narrador em descrevê-lo de maneira negativa, como se essa negação influenciasse a sua percepção do conceito de regionalismo.

Caminho em círculos. Sinto-me acuado pelos livros, esmagado pelas verdades que encerram. Foi por causa dos livros que nunca consegui entender-me com tio Salomão. Quando nossas disputas abrandavam, eu me tornava justo e generoso deixava os rancores de lado e reconhecia nele uma erudição solitária, um jeito próprio de ver o mundo e a civilização brasileira. Percebia seu esforço em busca do que é permanente e sobrevive ao furor das mudanças. E admirava o quanto ele insistia numa consciência regional, procurando desenvolver um pensamento e uma prática cosmopolita. Separado de um passado mítico e irrecuperável, esforçava-se por achar no presente um caminho para ele e seu mundo sertanejo (BRITO, 2009, p. 162, grifo nosso).

Apesar da descrição negativa, há certa contradição entre a admiração e a consciência de algo irrecuperável. As suas concepções sempre caminham em meio às contradições: por vezes o narrador parece expor toda a negatividade veiculada pela crítica sobre o regionalismo, em outras ele sutilmente o enaltece e mostra admiração. A contradição é manifestada pelo próprio narrador, quando afirma:

Mas essa trégua durava pouco tempo. Logo eu voltava a ser o intelectual pós- modernista desconfiado da cartilha do tio, temeroso de que ele me transformasse em mais um talibã sertanejo, desses que escrevem genealogias familiares e contam causos engraçados (BRITO, 2009, p. 162-163)

\section{Adonias, o sujeito perdido}

A narrativa de Galileia se constrói a partir do registro da viagem de três primos - Ismael, Davi e Adonias - à fazenda Galileia para o aniversário do avô Raimundo Caetano, mas, ao invés da comemoração, eles se deparam com o patriarca da família apodrecendo em seus últimos momentos de vida. Adonias, narrador da história, em sua viagem vai rememorando e revivendo fatos do passado. Esse sujeito está sempre em conflito com o seu lugar no mundo, dilacerado em seus pensamentos, pondo em dúvida sua ida à fazenda, ou seu retorno ao Recife, como pode-se perceber no seguinte trecho: "Possuo referências do sertão, mas não sobreviveria muito tempo por aqui. Criei-me na cidade, mas também não aprendi a ginga nem o sotaque urbanos. Aqui ou lá me sinto estrangeiro" (BRITO, 2009. p. 160). Suas tormentas o acompanham durante toda a narrativa: "Por que retornei à Galileia? Por que retornamos aos lugares que nos expulsam como aborto indesejado?" (BRITO, 2009, p. 142). Tais conflitos estão associados ao fato de esses sujeitos vivenciarem outras culturas e enxergarem o seu local com mais criticidade, influenciados pelo processo de modernização vivido, como destaca Carlos Roberto Vasconcelos:

\begin{abstract}
Uma vez marcados pela cultura exterior, os homens "traduzidos" viverão o dilema do voltar sempre, mas não ficar nunca. O fenômeno do partir está intrinsecamente ligado ao mundo globalizado, ao capitalismo, que oferecem ofertas sedutoras de conforto e conquistas. Inevitavelmente influenciados pela cultura original, tornar-se-ão críticos ferrenhos dessa cultura exatamente por conhecê-la de perto. Do convivio com o novo, serão sempre juizes a aferir valores e estabelecer comparações entre os sistemas de sociedade. Seus espiritos heterogêneos se converterão em permanentes adeptos do sincretismo, buscando novas formas de expressão, mais apropriadas às modernidades, desafiadoras do obsoleto e redefinidoras do sujeito social (VASCONCELOS, 2013, p. 66).
\end{abstract}

Ao longo dessa viagem, os personagens percebem um sertão transfigurado. No lugar do sertão arcaico e ultrapassado, começam a surgir as modificações geradas pela globalização, que, além de alterar a paisagem, modifica o modo de vida de um povo. Simultaneamente, esse local vai perdendo suas forças, não há nada no sertão, nem tampouco nas cidades vizinhas, conforme assegura o dono de um bar à beira do caminho: "la num ônibus da Prefeitura. Eu não possuo carro. De cavalo essa juventude não aceita andar. [...] Não existe mais roça, nem eles querem. Não existe mais gado, nem eles querem. Tem a cidade sem emprego" (BRITO, 2009, p. 38). 
O sertão vai modificando a sua paisagem ao longo do tempo, o seu povo passando por transformações, e essas vão modificando o modo de vida das pessoas: "Mulher em motocicleta carrega uma velha na garupa e tange três vacas magras. Dois mitos se desfazem diante dos meus olhos, num só instante: o vaqueiro macho, encourado, e o cavalos das histórias dos heróis, quando se puxavam bois pelo rabo" (BRITO, 2009, p. 8). As tradições vão perdendo suas forças, e o processo de modernização vai chegando a esses locais pequenos e marginalizados, alterando suas paisagens e o seu povo. Esse espaço, que vai aos poucos perdendo a sua pujança, parece ser intoxicado com processos advindos do mundo globalizado:

Ficamos em silêncio, olhando casas de luzes apagadas, com antenas parabólicas nas cumeeiras dos telhados. Eram bem poucas no planalto extenso, multiplicando-se próximo às cidades. Desejei bater à porta de uma delas, dar boa noite às pessoas, xeretar o programa a que assistiam. Não consigo imaginá-las atravessando a porta para os afazeres nos currais e roçados, depois de se intoxicarem de novelas. Despertados pela luz do farol, de vez em quando voam pássaros à nossa frente, voos rasantes, ligeiros (BRITO, 2009, p. 15).

\section{O personagem Adonias passa por toda a narrativa} de forma sempre conflituosa a respeito do lugar a que pertence, é um sujeito dilacerado, marcado por uma relação de pertencimento mal resolvida. Em alguns momentos parece esquecer o sertão e ser um médico urbano, mas ao mesmo tempo não consegue fazer isso: "Foi sempre assim, em todas as férias. O desejo quase erótico de retornar ao lugar onde nasci se misturava com o medo inexplicável de morte. [...] Chorava pelos cantos, pensava em voltar. Depois, não queria mais sair dali" (BRITO, 2009, p. 129). A desordem sobre o local ao qual pertence reflete, em alguns momentos, dúvidas sobre ser, ou não, um novo profeta sertanejo, que luta pelo seu povo e sua terra:

Uma cerveja com essas moças me fará bem, talvez me imunize contra a paranoia salomônica, o sentimento de que fazemos parte de outro Brasil, pobre e discriminado. No meio de toda conversa ele empurra seu discurso, fala que nos chamam de regionalistas apenas para diminuir o valor do que nós produzimos. Convenço-me de que leu em excesso os romancistas russos e sofreu indigestão. Doença que seria facilmente curada se trocasse uns amassos com alguma das costureiras. Elas nem ligam para o significado de autêntica cultura brasileira e outros desvarios, olham a triste figura que aparento, indiferentes às minhas ambiguidades, meu eterno dilema entre ser ou não ser um novo profeta sertanejo (BRITO, 2009, p. 170, grifo nosso).

Os personagens que migram e retornam são comparados com aves típicas do sertão nordestino, embora a todo momento exista uma necessidade de explicitar que eles tentaram cortar os laços com essa região e com o patriarca da familia: "Somos aves de arribação. Mesmo quando partimos sem olhar para trás, retornamos; quando imaginamos firmar os pés numa nova paragem, estamos de volta" (BRITO, 2009, p. 69).

A volta desses personagens pode estar ligada a uma relação umbilical presente em certas obras da tradição regionalista, nas quais o autor tem a necessidade de descrever esse local maternal, que serve de refúgio na mesma medida em que os expulsa. "Casa é refúgio, útero materno. Nela, tudo se oculta" (BRITO, 2009, p. 54). Essa necessidade intrinseca de retorno ao local no qual o narrador personagem passou uma boa parte de sua vida pode estar associada a uma relação sociopsicológica entre o autor e sua terra natal. João Claudio Arendt exemplifica a mesma relação, referindo-se ao prólogo de Iracema, de José de Alencar:

No prólogo de Iracema, em 1865, José de Alencar, [sic] faz considerações acerca da elaboração e da possivel recepção do romance ao seu amigo, Dr. Jaguaribe, que se encontra no Ceará. Um dos aspectos aí posto em relevo diz respeito à relação do romancista com sua terra natal: "Os meninos brincam na sombra do outão com pequenos ossos de reses, que figuram a boiada. Era assim que eu brincava, há quatro anos, em outro sítio, não muito distante do seu" (1974, p.102). É o "amor do ninho" que vincula Alencar ao espaço rural do Ceará, uma espécie de laço sentimental que nem o tempo e a distância conseguem romper - cuja razão talvez se encontre no fato de as relações dos homens com o espaço terem uma dimensão psicológica e sociopsicológica [...] (ARENDT, 2010, p. 185). 
Concomitantemente, a narrativa se constrói a partir de dois eixos temáticos - de um lado, recordações e revisitações a fatos passados, de outro, conflitos internos entre os personagens e seus locais de pertencimento - que influenciam nessa perturbação dos personagens. Sujeitos perdidos, dilacerados em suas relações, e conflituosos:

A embriaguez cessa de repente. Sem a chance de partir, tudo parece sombrio e feio; o coração se tranca, a boca amarga. Os dançarinos passam cantando e arrancam o Santo dos meus braços. Tento alcançá-los, mas eles desaparecem. Sinto-me sozinho. Procuro alcançar o outro lado da praça e encontro a mesma paliçada de motos. Recuo porque não consigo transpô-la. Já não sei que direção tomar. Até bem pouco tempo, o mundo em volta de mim era compreensível e amável. Agora, seu significado me foge por completo (BRITO, 2009, p. 236).

\section{Ismael, um nômade em conflito}

No decorrer da narrativa, ganha relevo a construção do personagem Ismael, filho bastardo de Natan com a india Maria Rodrigues, cuja paternidade nunca foi reconhecida. O pai biológico não acreditava no posicionamento da índia, que afirmava ser seu o filho que carregava em seu ventre. A partir disso, surge um distanciamento entre pai e filho, que não o aceita como tal. 0 avô, Raimundo Caetano, apesar da contrariedade de sua esposa, traz o neto para junto de si e o registra como filho. Assim, depois de passar parte de sua infância na tribo dos índios kanelas, no Maranhão, Ismael vai morar junto com o seu avô na fazenda Galileia. Toda a sua história nesse local é construída ao lado de seu avô, ao mesmo tempo em que os outros familiares o rejeitam como pertencente à familia:

[...] Maria Raquel bateu o pé e ameaçou sair de casa se trouxessem o bastardinho kanela para viver debaixo do mesmo teto em que ela vivia. Raimundo Caetano esperou dois anos, mas um dia ausentou-se por três semanas, retornando com um menino magricela e malvestido. Era Ismael. Ele mesmo escolhera o nome, e o registrara como seu filho legitimo e de Maria Rodrigues. A partir daquele dia Ismael tornou-se filho do avô, irmão do pai, e o nosso tio por direito. Natan, que não suportava ver-se repetido de forma tão fiel, passou a odiar o filho e a persegui-lo todos os dias em que habitou a Galileia (BRITO, 2009, p. 95).

Em seguida, Ismael vive parte de sua vida na Noruega, local em que se casa, constrói sua familia e perde tudo que tinha. A relação com Galileia sempre foi conflituosa, vários moradores da fazenda o olhavam com repulsa e o viam como o bastardo defeituoso. Apesar da rejeição dos familiares, Ismael exalta o seu passado com o seu povo e nesse local:

- Quando nos distanciamos de nossa origem, o reencontro com o passado é doloroso, quase impossivel. Sempre vivi aqui. Desde que nasci olho essa casa. Ela não me assusta porque faz parte de minha vida. Não é o seu caso. Adonias. Para você ela é um fantasma (BRITO, 2009, p. 150).

Em toda a história, Ismael mostra um conflito sobre o seu local de pertencimento, uma vez que, apesar de vivenciar culturas distintas e morar em outros locais, ele não consegue definir para onde retornar após a viagem à fazenda: "Teve a prisão, complicou minha vida. Não sei ainda onde vou. Minha filha mora lá, mas eu perdi a guarda" (BRITO, 2009, p. 73). Em conversa com Adonias, é questionado sobre uma traição ao seu povo, por enxergar o Inhamuns e seus familiares como sinônimo de justiça:

$$
\begin{aligned}
& \text { - Esse é o discurso mais careta que já } \\
& \text { escutei, Ismael. Em nome dos parentes } \\
& \text { que o rejeitam, você se orgulha até do } \\
& \text { massacre dos indios. Esquece que é } \\
& \text { um deles? } \\
& \text { - Os indios daqui foram incorporados. } \\
& \text { - Foram dizimados. } \\
& \text { [...] } \\
& \text { - Você sente saudade desse tempo? } \\
& \text { - Sinto. } \\
& \text { - É estranho, nem dos Inhamuns você é! } \\
& \text { Passoua maior parte da vida no Maranhão, } \\
& \text { e depois na Noruega (BRITO, 2009, p. 17). }
\end{aligned}
$$

O personagem demostra todo o seu apego ao sertão, pois, mesmo vivenciando outras culturas, conhecendo outros locais, não consegue desvincular-se desse local, esse sertão que o acompanha em pensamento. Quando, na Noruega, é preso por consequência do uso de 
drogas e de espancar a sua esposa, Ismael usa das memórias do sertão para livrar-se da depressão. É como se esses pensamentos servissem de consolo íntimo e as lembranças desse espaço ajudassem a sobreviver ao caos:

- Adonias, eu vou dizer os nomes das árvores que conheço. Sei detalhes das folhas, dos troncos e da floração de cada uma delas. Não pense que essa lembrança é inútil. Ela me serviu muito, no tempo que fiquei preso na Noruega. Quando não tinha nada o que fazer. eu imaginava a floresta, as plantinhas mais bestas. Escrevia os nomes num caderno, desenhava as flores e chorava arrependido do rumo que dei à minha vida. Só desse jeito eu aliviava a depressão (BRITO, 2009, p. 12-13).

Apesar de ser esse sujeito multicultural, o personagem faz do sertão a sua ótica para ver o mundo, de modo que chega a tecer comparações entre a Noruega e o sertão, mostrando que apesar de serem locais distintos possuem pontos de ligação. Para Ismael, é como se o sertão estivesse dentro dele:

A Noruega é um sertão a menos trinta graus. As pessoas de lá também são silenciosas, hospitaleiras e falam manso. Habituaram-se aos desertos de gelo, como nós à caatinga. A comparação parece sem sentido, mas eles também olham as extensões geladas, como olhamos as pedras. A nossa pele é marcada pelo sol extremo, a deles pelo frio. Acho que as pessoas são as mesmas, em qualquer latitude.

- Mudam as culturas, as crenças, o grau de civilização.

- Eu falo da essência (BRITO, 2009, p. 73).

Em virtude dessa relação com o seu local de pertencimento, Ismael relata sua dificuldade em adaptar-se a novos locais, mostrando que o sertão está dentro de si, como se fosse uma doença incurável: "É preciso muito tempo para se gostar de um lugar. Eu nunca me acostumei à Noruega. Dizem que ela é melhor que isso aqui. Eu não acho. O sertão a gente traz nos olhos, no sangue, nos cromossomos. É uma doença sem cura" (BRITO, 2009, p. 19). É interessante perceber que a definição do sertão como uma doença sem cura traz consigo certa ambiguidade. Tratase de algo negativo, que o prende a um dado espaço, mas, simultaneamente, é aquilo que o faz enxergar o mundo com individualidade, um local usado como referência em sua vida, pelo qual ele tem mais estima que os demais.

Durante toda a narrativa, Ismael vai mostrando suas dúvidas a respeito de para onde retornar e o que fazer. Em todos os locais por que ele passa sente-se perdido, porém, no fim da narrativa, é o único que aparentemente fica em Galileia. Podese dizer que o sertão seria a sua única maneira de se reencontrar como sujeito:

- Não sei ainda pra onde vou. Na verdade, eu continuo sem lugar. Não tenho o que fazer no Maranhão, no meio dos kanela. Saí de lá pequeno, e só voltei porque me expulsaram daqui. Afora os vínculos de sangue e as marcas no corpo, nada me liga a eles (BRITO, 2009, p. 132).

Além das indecisões, o personagem sente uma necessidade de expurgar as marcas indigenas que carregam o seu passado. Para ele, o sertão é sua origem: "- Você é mais sabido do que eu, primo. Fez doutorado na Inglaterra, mas eu aprendi como os antigos da familia, sozinho, por esforço próprio. Li os livros que você nunca se interessou em ler" (BRITO, 2009, p. 17).

Apesar de todos os conflitos vivenciados. Ismael enaltece o seu desejo de fixar-se na fazenda Galileia, deixando de lado o passado problemático que gira em torno de seus familiares: "- Eu gosto mesmo é daqui. Se fosse possivel ficar, eu ficava. Botava o orgulho entre as pernas e começava uma vida nova" (BRITO, 2009, p. 132).

Ao final, as lembranças desse sertão permeiam toda a narrativa, os personagens revivem as memórias de sua infância e as atrelam ao processo de modernização contraditória que assola esse local: "O rádio fala alto, a televisão oferece produtos, o liquidificador gira as hélices, a forrageira estrala, as galinhas cacarejam, as vacas mugem, relincham os cavalos, latem os cachorros" (BRITO, 2009, p. 99). A tradição entra em conflito com a modernização, a tecnologia que vem de fora não tem serventia nesse ambiente, a não ser para corromper o seu povo, como relata o dono de um bar sobre seu filho, que foi preso por roubar um aparelho celular, mesmo sem saber utilizá-lo: 
- Meu filho quase se mata por nada, por esse trastezinho que até pouco tempo atrás nem existia pra gente. Mas agora existe, e ele desejou um. É o Diabo quem inventa essas coisas, só pode ser. E também é o Diabo quem tenta a gente pra querer o que não precisa. Ele aparece na televisão, ludibriando, prometendo maravilhas, mandando comprar, fazer qualquer sacrificio para possuir essas porcarias. A cada hora inventam uma coisa diferente. Nosso menino esqueceu a honra. Esqueceu tudo. Roubou o celular e está preso. Quando viu que não aguentava a cadeia - chamam com outro nome a prisão pra menores, mas é pior que cadeia tentou se enforcar. Passou uma corda no pescoço e não morreu porque os guardas chegaram a tempo. Da segunda vez, tomou água sanitária e foi internado num hospital. A mãe está com ele. Certas horas eu esqueço que é nosso filho, de tanto desgosto. Tudo por causa de uma coisinha dessas que fala com quem a gente nem vê. Deve ser o Diabo quem chia no ouvido das pessoas. Só pode ser ele. E meu filho caiu na tentação. Acho bom que ele morra, que nem volte mais pra casa. Fique por lá mesmo, no meio dos que não prestam (BRITO, 2009, p. 40)

O sertão, apesar de modificado de forma conflituosa, conduz esses personagens a rememorar os fatos vivenciados nesse espaço e traz à tona combates internos que guiam todo o romance. Trata-se de uma viagem existencial, que não é para um local, mas para um tempo passado, para uma outra maneira de ser e existir desencadeada pela experiência espacial:

\begin{abstract}
É estranho como o sol desaparece rápido no sertão. Mal nos preparamos para a noite. Voam pássaros que desconheço, raposas atravessam a estrada, besouros batem no para-brisa do carro. Não identifico nenhum pio de ave acima da música. Meu pavor aumenta. Para onde vamos? (BRITO, 2009, p. 11)
\end{abstract}

\section{Considerações finais}

Em consequência das elaborações críticas negativas em torno do regionalismo, é perceptivel como Ronaldo Correia de Brito procura desvincular-se de tal corrente literária. Contudo, pode-se perceber que sua obra recupera temas, espaços, imagens e topoi clássicos do regionalismo, ou seja, ela possui inúmeros pontos de ligação com a tradição literária regionalista. Isso, porém, não a torna restrita, tampouco reduz suas capacidades expressivas, o que corrobora os estudos que afirmam que apenas rotular uma obra como regionalista não determina sua qualidade. Apesar disso, o autor, em entrevistas analisadas, demonstra desconforto em associar sua obra a tal vertente literária, o que se manifesta, inclusive, em trechos do romance Galileia, nos quais o regionalismo ganha destaque de forma negativa, podendo encaminhar o leitor a juizos de valor sobre a corrente literária.

Como visto, o romance se constrói a partir da recuperação de temáticas historicamente associadas ao sertão nordestino, sempre de forma intimamente ligada a conflitos internos dos personagens, que se mostram dilacerados com o sertão transfigurado, diferente do local que alimenta seus imaginários. Carlos Alberto Vasconcelos dá ênfase a esse processo em seus estudos:

Hipoteticamente, tempo e espaço se revelam abreviados. As definições de campo e cidade tornam-se cambiantes e o próprio sertanejo sente-se vacilante quanto ao seu pertencimento a um lugar a uma sociedade. As lembranças e reminiscências que formam a amplitude da Memória vão ao encontro do que o mundo globalizado reivindica como identidades. Ronaldo Correia de Brito, por meio principalmente do personagem-narrador Adonias, não reivindica o sertão mítico e imutável, tão decantado em prosa e verso. Sua proposta, com o romance, não é, definitivamente, a preservação (talvez nem mesmo a tradução), mas a revelação de um universo que, com tudo o que contém de mítico, místico ou conservador, está sujeito a transformações (VASCONCELOS, 2013, p. 85).

Os personagens vivenciam uma nova realidade. um sertão invadido pela modernidade; são sujeitos confrontados com o processo de modernização que invadiu aquele local e modificou suas paisagens. Essas experiências afetam sua aceitação daquele espaço, da sua realidade, da sua cultura, o que termina por desencadear relações de pertencimento mal resolvidas. Tais conflitos influenciam a construção desses personagens, sujeitos perdidos nos conflitos 
Hayonara Medeiros · André Tessaro Pelinser

da tradição e da modernidade. Sendo assim, a dilaceração existencial de personagens como Adonias e Ismael é um dos marcos da narrativa e o determinante para a condução do romance, o qual recupera e revitaliza o espaço sertanejo, a partir de questões próprias à contemporaneidade.

\section{Referências}

ANDRADE, Mário de. Regionalismo. In: SCHWARTZ, Jorge. Vanguardas Latino-americanas: polêmicas, manifestos e textos criticos. 2. ed. rev. e ampl. São Paulo: EDUSP, 2008. p. 553-554. https://doi. org/10.5195/reviberoamer.1998.6170

BRITO, Ronaldo Correia de. Galileia. Rio de Janeiro: Objetiva Ltda, 2008. 236 p.

LAJOLO, Marisa. Regionalismo e história da literatura: Quem é o vilão da história?. In: FREITAS, Marcos Cezar de. Historiografia brasileira em perspectiva. São Paulo: Contexto, 2001. p. 297-327.

LEITE, Ligia Chiappini Moraes. Velha Praga? Regionalismo literário brasileiro. In: PIZARRO, Ana. América Latina: Palavra, Literatura e Cultura. São Paulo: Memorial, 1994. p. 665-702.

MELO, José Inácio Vieira de. Ronaldo Correia de Brito - o código do livro dos homens. Jornal Tribuna Feirense, Feira de Santana, BA, 17 jul. 2005. Tribuna Cultural. Disponivel em: http://www.jornaldepoesia. jor.br/jinacio18.html. Acesso em: 30 maio 2019.

PELINSER, André Tessaro. Olhares sobre o regionalismo literário brasileiro: uma perspectiva de estudo. Antares: Letras e Humanidades, Caxias do Sul, n. 4. p. 106-120, jul./dez. 2010. Disponivel em: http:// www.ucs.br/etc/revistas/index.php/antares/article/view/569. Acesso em: 10 ago. 2019. https://doi. org/10.18226/19844921.v11.n24.03

PEREIRA, Lúcia Miguel. Regionalismo. In: PEREIRA, Lúcia Miguel. História da literatura brasileira: prosa de ficção: de 1870 a 1920. São Paulo: Editora da Universidade de São Paulo, 1988. p. 175-183. https://doi. org/10.11606/issn.2318-8235.v57iop286-292

SANTINI, Juliana. Realidade e representação no romance regionalista brasileiro: tradição e atualidade. O eixo e a roda, Belo Horizonte, v. 23, n. 1, p 115-131, 2014. Disponivel em: http://www.periodicos. letras.ufmg.br/index.php/o_eixo_ea_roda/article/ view/5908. Acesso em: 10 ago. 2019. https://doi. org/10.17851/2358-9787.23.1.115-131

VASCONCELOS, Carlos Roberto Nogueira de. Sertão de pedra e argila: tradição, ruptura e modernidade no romance Galileia, de Ronaldo Correia de Brito. 2013. 92 f. Dissertação (Mestrado em Letras) - Universidade Federal do Ceará, 2013. https://doi. org/10.12957/cadsem.2019.38557

VENCEDOR rejeita o rótulo de regionalista. Folha de S. Paulo, Ilustrada, São Paulo, ago. 2009. Disponivel em: https://www1.folha.uol.com.br/fsp/ilustrad/ fq0508200916.htm. Acesso em: 10 ago. 2019.

\section{Endereço para correspondência}

Hayonara Medeiros/André Tessaro Pelinser

Universidade Federal do Rio Grande do Norte

Rua Manoel Lopes Filho, 138

59380-000

Currais Novos, RN, Brasil 